\title{
Finding a 'Normal' Woman: Selection Processes for Board Membership
}

\author{
Inge Claringbould • Annelies Knoppers
}

Published online: 21 March 2007

(C) Springer Science + Business Media, LLC 2007

\begin{abstract}
The higher the organization level, the lower the percentage of women in governance. The purpose of the present study was to explore how men and women negotiate women's 'fit' as candidates for boards of national sport organizations. We based our analysis on in- depth interviews with male chairs and female board members. The results provide evidence that men can control boards by affirming and negating affirmative action policies and by framing the process of recruitment and selection in such a way as to reproduce the male-dominated culture in the board. Women, in their turn, tend to negotiate their entry by distancing themselves from their gender and proving their 'fit.'
\end{abstract}

Keywords Gender Governance $\cdot$ Sport .

Recruitment and selection

Although a considerable amount of research has explored the under-representation of women in senior management (see for example, Martin, 2001; Power \& Butterfield, 2003; Rutherford, 2001; Wacjman, 1998), relatively less research has focused on the gendering of boards of directors. This is puzzling because the board of directors of an organization formally constitutes the pinnacle of organizational power, oversight, and decision making (Acker, 1990; Hoye, 2002; Sarra, 2005; Sheridan \& Milgate, 2003). Boards of directors are a fertile site for the study of gender relations because these are places of organizational power, and, in essence, they determine the goals of senior management.

I. Claringbould $(\bowtie) \cdot$ A. Knoppers Utrecht School of Governance, University of Utrecht, Bijlhouwerstraat 6, 3511 ZC Utrecht, The Netherlands e-mail: I.E.C.Claringbould@uu.nl
Boards of directors provide the general framework for organizational policies and conditions under which an organization operates and functions. As the higher a position in the organizational hierarchy, the fewer the number of women in those positions, it is not surprising that the percentage of women who are members of national boards of directors is lower than the percentage of women who are senior managers (CDWI, 2004). Yet there is growing recognition that women are stakeholders in all types of organizations from corporate to volunteer and that they must be part of governing processes as well. Corporations have been aware of the need for diversity in the rank and file and in the client base, but have only recently begun to address the shortage of women in governance. Daily and Dalton (2003) have argued that boards of directors need women members because they add unique strengths to the board that men do not have, because their presence signals a commitment of the board to gender equity in the entire organization, and because their presence enhances organizational productivity.

Yet women directors are scarce (CDWI, 2004). Although $73.5 \%$ of the 200 largest companies in the world have at least one woman director, only $10.4 \%$ of all board members in the Fortune top 200 are women. The American companies that belong to the Fortune Global 200 have more women directors $(17.5 \%)$ than European companies, who typically have less than one-half of that number. Women for example, comprise $6.3 \%$ of the corporate board members in The Netherlands. Such gender skewness has stimulated research on gender and governance (see for example, Burke \& Mattis, 2000). Sheridan and Milgate (2003) contended that, as most directors were previously senior managers, the lack of women in corporate boards can be attributed directly to the relatively few women senior managers. 
Most of this research has focused on corporate boards of directors, however little attention has been paid to the gendering of boards of nonprofit organizations. Yet membership of such boards, although perhaps not as prestigious as corporate governance, still carries with it prestige and decision making power, especially at the national level and in sport. National (sport) governing boards constitute the major decision making bodies and impact the ability to deliver services related to the primary activity of the organization (Hoye, 2002). In addition, such boards are increasingly (although not totally) similar to corporate boards, as nonprofit organizations are also moving toward professional management practices as they cope with a multiplicity and complexity of demands (Inglis, 1997; Kikulis, 2000). The change toward such professionalism may vary by sector and by the primary activity of an organization. Hoye (2002) has noted that nonprofit boards are usually socially diverse because they serve a diverse constituency. Boards of sport organizations seem to be in a unique situation however. For example, although the percentage of men and women participating in Dutch voluntary organizations is similar and although women are underrepresented $(26 \%)$ on most boards of nonprofit organizations, their representation on sport boards is the lowest (11\%) in the voluntary sector (Merens, Cuijpers, \& Boelens, 2004; Nuijten, Lucassen, \& Van Kalmthout, 2004). ${ }^{1}$ These statistics may be related to the nature of sport as a primary activity of an organization. Kikulis (2000) found that the shift to professional governance of national sport organizations was hindered by values that are deeply rooted in its traditions. Gender is one dynamic that is deeply embedded in the structure of and meanings assigned to sport. Not only does sport have a bifurcated structure (men's sport and women's sport), but, as the data indicate, its governance is strongly gender skewed, especially at national and international levels. The Netherlands is not an exception.

This visible lack of gender equity in sport governance worldwide led the International Olympic Committee (IOC) to create policies in 1996 that set specific quotas for the

\footnotetext{
${ }^{1}$ Women comprise 28 and $11 \%$ of Dutch board members of local and national sport associations, respectively (Nuijten et al., 2004). In 2005, about one-third of the national sport associations had no women in their boards at all. Almost one-half of them had only one woman board member, and only two (rowing and field hockey) had more than two women. The total percentage of women members for these boards was $14 \%$ in 2005 , an increase of $2 \%$ since 2002 . In addition, when women become members of local, provincial, or national boards in sport, they are more likely to become secretary $(37 \%)$ than chair $(10 \%)$ of the board. Thus, not only is the gender ratio of boards of directors skewed, but a gendered division of labor occurs at all levels of sport governance when women are board members. Sports with a balanced gender ratio of athletes had more women board members than did boards of male-dominated sports.
}

percentage of women board members to stimulate international and national sport federations to appoint women to its boards. The absence of women board members is, therefore, no longer deemed acceptable in sport governance. These recommended quotas legitimized women's presence and candidacy, and thus seem to have contributed to an increase in the number of women board members in high-level sport governance (White \& Henry, 2004). ${ }^{2}$ Although these practices of inclusion and exclusion of women board members in sport governance have been the target of policies, relatively little scholarly attention has been paid to the social dynamics that contribute to the under-representation of women in sport governance. Such attention is necessary, however, to ensure that the factors that influence the gendering of boards are made visible and can be targeted for change. In addition, a focus on the gendering of sport governance can also contribute to theory building about the ways in which women are excluded from strategic positions in nonprofit organizations and the ways that such exclusions may be linked to the gendering of the primary activity of the organizations (Acker, 1990). The legal structure of sport organizations and many of the changes that occur in these organizations, such as downsizing, mergers, individualization, professionalization, specialization, and increasing demands on productivity, are similar to those that occur in nonsport organizations (Verweel, 2006).

The focus of the present study was on the gendering of governing boards of national sport associations in The Netherlands. This country is especially suitable for study because its sport system is based on sport clubs and is not conflated with educational institutions, as is the case in the United States. Dutch amateur sport is organized in a voluntary club (local) and association (national) structure. The relevant national sport association provides the competitive structure.

\section{Theoretical Approach}

The results of practices of exclusion in organizations, occupations, and activities often become visible in structures when they result in skewed (gender) ratios (Kanter, 1977). Social groups are, however, rarely totally excluded. Inclusion and exclusion are part of a dynamic process of

\footnotetext{
${ }^{2}$ Since 1996, 64 \% of National Olympic Committee's (NOC's) and International Federations (IF's) worldwide took measures to increase the number of women in their boards. These policies recommended that women should comprise at least $10 \%$ of National Olympic Committees and International Federations by 2001 and $20 \%$ by 2005 (White \& Henry, 2004). A record number of women (71\% of new board members) have become board members in NOCs and IFs since these measures were taken. In 2003 women comprised $10 \%$ of the board members of $62 \%$ of NOC's and $41 \%$ of IF's (White \& Henry, 2004).
} 
interactions created by organizational members through which organizational members receive information about who belongs at which position and about images and values incorporated in organizational structures. In addition, individuals learn to engage in identity work as they understand where they belong and which behavior is expected (see for example, Acker, 1990, 1992; Gamson, 1997). Such processes are shaped by power relations between social groups marked for example by gender, race/ethnicity, age, and often designated in terms of a dominant group and a subordinate group. Although members of minority or subordinate social groups are formally included in organizational membership, they can still be marginalized through patterns of interactions and the creation of meanings or 'common sense' (Knoppers \& Anthonissen, 2005). For example, a woman board member can be marginalized in interactions when men perform a certain form of masculinity, such as discussing cars during meetings, engaging in paternalistic behavior, or telling sexist jokes (Martin, 2001, 2003).

Members of social groups who dominate positions of leadership may create practices of exclusion, dominance, and marginalization through unintentional and strategic behaviors (Itzin, 1995; Rutherford, 2001). As such, they 'police' and control the boundaries of access to the highest positions within an organization. This boundary policing influences the different ways in which dominant and marginalized social groups experience organizations. For example, male managers and board members tend to associate the low number of women in leadership positions with women's lack of experience and/or commitment, whereas a majority of female managers and board members attribute this skewness to discrimination and resistance to women occupying such positions (Acosta \& Carpenter, 2005; Sheridan \& Milgate, 2003). In addition, men rarely see their own gender as a source of privilege, whereas women see that men as a group have access to certain resources that they themselves do not (Kanter, 1977; Martin, 2001). Such differences in perception between dominant and subordinate groups impact the behavior of the two groups, especially if the latter want access to positions controlled by the former.

Although most research in the area of gender and governance has explored how women experience being members of boards of directors (see for example, Burke \& Mattis, 2000), relatively little research has focused on the ways in which women negotiate access to these positions of leadership in general and specifically in the nonprofit sector. How do members of a dominant group police access to positions of power in such a way that a select few members of a subordinate group are admitted, and how do members of subordinate group negotiate their entry? The lack of women in positions of power has often been attributed to organiza- tional culture, although the ways in which entry is negotiated may play a significant role as well. A study of ways in which women as a subordinate group attain positions of leadership is essential to understanding mechanisms of exclusion from positions of power and decision making. In the current study we used the perspectives of men (dominant group on sport boards) and women (subordinate group) to explore the process by which women become members of boards of directors of national sport associations. This process of inclusion requires members of both the dominant and the subordinate group to negotiate recruitment and selection criteria.

Negotiating gender and fit

Witz $(1990,1992)$ argued that inclusion (fit) and exclusion (lack of fit) are the result of processes of negotiation between dominant and subordinate groups. She linked fit/ lack-of-fit to material and ideological privileges that accrue to individuals based on intersections of social relations such as gender, ethnicity, and/or sexual preference. Processes of negotiation are gendered in two ways because both people themselves and the criteria for inclusion and exclusion are gendered. Dominant meanings and images assigned to qualities that are associated with gender result in perceived congruence of men and women with specific activities and jobs and strengthen assumptions that one group is a better fit for positions than the other is. A lack of fit is said to occur when the gender of a group of individuals does not correspond with gendered images associated with a position or job. Managerial positions, for example, are associated with objectivity, rationality, logic, and competence that are traditionally linked to forms of White middle to upper class masculinity and tend to explain why more men than women hold high and powerful positions of leadership (Collinson \& Hearn, 1996). Managers, who associate women with unpaid or lower paid work, with families and domesticity, with emotions and subjectivity and/or, with a decrease in the status of a profession or occupation, may, therefore, marginalize or exclude women from specific positions of leadership because they do not 'fit' the profile of a manager (Acker, 1990, 1992). Such perceptions of lack of fit, therefore, sustain a gendered structure of the labor market and domestic life in both management and governance. Witz (1990) showed how gender, fit (position), and dominance are inextricably bound up with each other and are constantly negotiated by the dominant and subordinate groups.

An accumulation of privileges allows a dominant group, such as White middle to upper social class men, to appropriate resources and shape opportunities that subsequently make them the ideal candidates for certain positions, which then results in the structural division of labor in organizations. In other words, they collectively and strategically use their positions of privilege to mobilize power and to exclude 
subordinate groups. ${ }^{3}$ This includes access to board membership and to certain types of board positions (division of labor).

Subordinate groups are not powerless, however. They may (need to) negotiate strategies to enter positions or occupations from which they were originally excluded. These negotiations are also gender-loaded when women attribute stereotypical feminine qualities to certain jobs to construct their own fit. For example, by framing coaching as an activity that requires caring and nurturing, women coaches constructed women as a better fit than men for coaching youth sport (West, Green, Brackenridge, \& Woodward, 2001). Yet members of a subordinate group can also engage in behaviors that negate stereotypes to show that they are different from the rest of their group. For example, women may behave in ways associated with male managers to prove their capability and to show they are not like most women. Women's use of behaviors commonly associated with either gender may, therefore, be situation-specific as they negotiate gender to show that they "fit" certain positions of leadership. Thus, they negotiate inclusion for a position from which they were originally excluded (Witz, 1990, 1992). The use of Witz's theory may, therefore, provide insight into the gendered processes of negotiating fit and marginalization.

In the present study, we used Witz's perspective to look at ways in which women negotiate their "fit" to become members of executive boards of national sport associations. Specifically, which strategies are used by the dominant and by the subordinate group to negotiate selection of women to boards of directors of national sport organizations?

\section{Method}

\section{Procedure}

The data were collected between fall 2003 and spring 2005 with the use of semi-structured interviews with board members of Dutch national sport organizations. The purpose of these interviews was to obtain insight into the ways in which members of dominant and subordinate groups negotiate meanings when a member of the subordinate group attempts to enter the dominant group. The selection of both groups of informants, male and female board members, was based on the gender ratio of their sport, type of sport (individual or

\footnotetext{
${ }^{3}$ The term exclusion refers mainly to physical, quantitative aspects of participation, although non-participation does not exclusively refer to exclusion. The term lack-of-fit emphasizes these aspects and refers to normative, qualitative aspects of participation. Therefore we prefer to use the term inclusion/exclusion, instead of fit/lack-of-fit, when referring to the quantitative presence/absence of (in this case) women. And we use the term fit/lack-of-fit to refer to the wider, normative process in which inclusion/exclusion takes place.
}

team), popularity of the sport, and availability for participation in the study. Men outnumber women sport participants in all sport organizations. As there are no popular sports that women dominate numerically, we chose two sports where the rates of participation are similar for men and women. The remaining sports are male-dominated. Therefore, the selected sport organizations reflected the gender composition of Dutch national sport organizations. ${ }^{4}$ Every selected board member was willing to participate in the study. The interviews lasted about 60-90 $\mathrm{min}$.

\section{Participants}

Those selected for these interviews belonged to either the dominant or the subordinate group. Twelve male chairs of national boards were interviewed about the selection processes of new board members. We assumed the chair of a board is best able to articulate selection procedures and plays a crucial role in this process and board culture. In the present study we assumed that they represent the dominant group. All chairs were men because there were no women chairs when the data were collected.

We also conducted semi-structured interviews with 12 women who were the highest-ranking women board members in these Dutch sport organizations. Eleven of the 12 women had at most one female colleague on the board. These women therefore represented the subordinate group in this analysis.

\section{Profile of the dominant group}

All interviewed chairs were former athletes. Most of them had also been a coach or member of a jury in their sport and had been a board member in- and outside sport. The men varied in age between 55 and 68 years, with one exception who was in his 40s. Ten men had a partner (female), and most of them had children although they were no longer at home. All but one participated in boards where men were a large majority, that is, a range from no women at all to a maximum of two women.

\section{Profile of the subordinate group}

All of the women had been athletes in their sport (two at the elite level). Fifty percent of them had also been a coach or a member of a jury. Seven of those interviewed were the only women on the board, and while five had at least one female colleague. The women varied in age between 32 and 66 years. They had held voluntary positions of leadership in sport and/or non-sport organizations. Ten had a male partner when they became a member of a board. Two-thirds

\footnotetext{
${ }^{4}$ We do not name the selected sports to protect the anonymity of those interviewed.
} 
of the women had children, but, of these, only three combined having (small) children at home with a board membership. All but two of the women engaged in paid work (in law, finance, management, government, or ran their own business), although not always full-time during their tenure on the board. Many women were used to operating in a male-dominated world. One woman said: "In my whole career I've always been one of the few women, so that [skewness] is a normal situation for me. I don't even notice it any more."

\section{Interviews}

The interviewer focused on career and life choices and on the strategies these men and women used. Comparable topics were discussed with both groups (see Appendix for a list of topics). In the interviews with the 12 male chairs, special attention was paid to their attitudes towards related policies like affirmative action, and to their explanations. In addition, attention was paid to the procedures that were used to select members of the board of directors, and to their attitudes towards changes in gender ratio of their board. In the interviews with the women special attention was paid to the ways in which they were recruited and selected, how they negotiated their entrance and the factors that influenced their decision to join the board.

The interview data were analyzed after every interview to determine the extent to which recurrent patterns occurred in the data. We continued to conduct interviews until no new information appeared (saturation). We, therefore, assume that the resulting data reflected the attitudes of most male and female board members of national sport associations in The Netherlands.

Witz's (1992) notion of negotiating fit was used to analyze the various strategies used by the dominant group (male chairs of national sport associations) to include women and by the subordinate group (women members of national boards) to become board members. The results reveal how men and women candidates negotiate their notions of "best fit" with each other. In our presentation of the data, we use quotes that best illustrate the various themes.

\section{Results}

Strategies of the dominant group

Witz $(1990,1992)$ argued that a dominant group, in this case male board members, tends to use various strategies to ensure social homogeneity in a position or occupation. The incumbent board members in the current study tended to police the boundaries of entry with the use of two strategies. One such strategy pertained to the use of affirmative action policies and the other was their use of recruitment and selection procedures.

\section{Affirmative action policy}

Most chairs, especially those involved in governing a gender-balanced sport, acknowledged the importance of the representation of women in their boards. They reasoned that a board needs to represent the entire membership and not just one-half of their members. Some were convinced that women board members were needed because they are better able than men to look after the interests of women's sport. They claimed that the issue of women board members was often discussed when there was a board vacancy. The chairs that supported affirmative action policies attributed the increase in the number of women board members to these policy measures. ${ }^{5}$ Such measures included the selection of a woman when a male and female candidate were judged to be similar or when replacing a departing woman board member. At the same time some chairs insisted that "qualities are never equal" and that it is very difficult to find qualified board members, especially women. As one of them said: "Because it is very difficult to find a [good] board member, affirmative action is of little use. You are happy to have any candidate with the right qualifications."

These chairs ascribed relatively little power to themselves for the implementation of affirmative action policies, however. Support of the other board members for affirmative action was deemed essential if women are to be selected. As one chairman said: "Women can be found if you look for them, but board members must be willing to select them." Another chair, who acknowledged the importance of women board members and affirmative action, blamed his colleagues for the lack of results. He said: "If we had an affirmative action policy, it would probably be pushed aside, because we think other matters are more important." These chairs not only attributed the lack of support by their colleagues for the under-representation of women board members but they narrowly circumscribed the conditions under which women would be selected, that is, only if these women bring qualities to the board that current board members do not possess. Most of the chairs showed little interest in actually implementing affirmative action measures. They argued that implementation should not be based on the number of women board members, but on the quality of the women candidates. In addition they contended that the implementation of affirmative action policy might work against women and/or that women might not have the

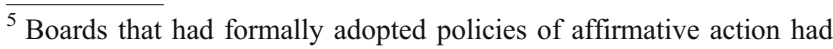
more women members than those boards that had not done so. Sixtythree percent of national sport governing boards with affirmative action procedures in place and $45 \%$ of boards without such policies had at least one woman member.
} 
ambition to be a board member. As one of them said: "I have seen women enter boards as a result of affirmative action policy, but that had little to do with quality, but with priority. How many incompetents were selected as a result of this policy?"

Even when a board supported affirmative action measures and a qualified woman was available she was not automatically selected as the following example illustrates. A chair explained that his board wanted more than one woman board member:

We prefer a woman when candidates have equal qualifications. Having more women is good for our image. Others might get the idea we are a club of only males. I think it is important to change it, if you have a male-only image. I personally recruited the board members that joined the board in the last few years. We had found a woman candidate who was a chair of a very large sport club. If we had taken her, we would have had two women by now, but we chose someone else [a man] because I was convinced he could add quality to the board.

Later in the interview he continued:

If someone leaves the board now, we will certainly look for a woman. I would support having at least two women in our board; they bring a different perspective. We might be able to ask the woman again, who was available for our last vacancy. She might be appropriate for the portfolio of handicapped sports. That position may become available soon, although we already have a man in mind for that portfolio ....

Although this man was convinced that his board engaged in affirmative action, the example shows that this intent may not translate into an increase in the number of women on a board, due to the recruitment and/or selection processes of the board. It is not surprising then that most chairs were convinced that the number of women in boards will change by itself, without policy measures. Their support of affirmative action in theory and their failure to support it in practice illustrates a preference for what Kanter (1977) calls 'homologous reproduction,' that is, a continued preference for member of the dominant group because they are the 'best' fit. The same can be said for their methods of recruiting new members.

\section{Recruitment}

Most boards use formal and informal methods to find the right candidate. They formally announce a vacancy a few months before the formal selection procedures begin. They ask individuals they know to be a candidate, and they ask sport clubs and other sport organizations to nominate candidates. They use internet, sport assemblies, and adver- tisements in newsletters. This formal procedure usually does not yield many results. The board then follows a more informal route with use of their own networks. A chair described a common procedure:

We used to use the volunteer leisure job vacancy bank, but that rarely gave good results, so now we look in our own networks, but you have to consult your colleagues about that. You can not just bring in a complete stranger for an important position.

Another chair described the recruitment procedure as follows: "You look for people who are more your own age and have a perspective that can add something to the board." One of the chairs explained why he supported this procedure: "A candidate must be supported by everyone in the board because we are a circle of friends." In this way as long as there is no necessity to change their way of governing, boards tend to reproduce themselves.

Sometimes, however, the need to have a woman alters this procedure. A chair attributed his own success in adding two women board members without much of a hassle to his own perseverance and networking. He said: "If you spot a qualified women, you must try to keep in contact with her so that you can ask her when you need her." It is interesting that all of the women board members referred to in these interviews were asked to become board members because of their gender and because of their skills. The required skills are formally part of the selection procedures.

\section{Selection}

Most boards draw up formal selection criteria for each vacancy. These include clarity of vision for the future of the association and sport, ability to see 'the bigger picture,' experience in governance, and affinity in the sport. Being a board member requires possessing a mix of suitable skills, knowledge, attitude, and available time. A chair said:

Having a job in governance or politics or in companies is handy, for example. A candidate with experience in governance or politics is important for our networks and for getting permission to do things while insiders in companies help us with sponsorships.

All chairs declared that the quality of the candidate is crucial for the selection. By quality they meant that the candidate possesses knowledge of the sport, is acquainted with the nature of the position, has experience in governance, and has the necessary personal qualities. Their quality criteria are those associated with high level jobs in society, where status, reputation, and networks are important. This implies that, by selecting candidates who do these kinds of jobs, more professionalism, power, and money are added to the sport. Candidates must, therefore, be perceived to add 
value to the board. In that sense, they may be different than other board members but at the same time their presence must not change the board culture, as most incumbent board members value it. Consequently, anyone who becomes a board member must adapt to this culture. Although this 'fit' counts for all candidates, the physical bodies of members of a subordinate group represent another culture and dominant societal associations with that physicality. So, if a woman candidate becomes a board member, she must be able to adapt to this culture, although physically she does not 'fit.' A chair warned that selecting a woman only because of her gender and not the 'fit' can be disastrous:

To choose a woman just because she is a woman is the most stupid thing you can do. Such a person must be able to see how the current board members work together. If there is a women who fits in there, it is fine.

Obviously then the dominant group of men determine criteria for board membership, but do so in a contradictory manner. They want more of the same, added value that is congruent with board culture, and yet also want women whom they see as 'different.' They want women because they are morally obliged to have them, but, at the same time, they want the board culture to remain the same. This gate-keeping strongly influenced the ways in which these women negotiated their entry on to these boards.

\section{Strategies of the subordinate group}

We asked women board members about their perception of the recruitment and selection process and about their strategies for furthering their own candidacy in these processes.

\section{Recruitment}

The data show that all of the interviewed women were members of (predominantly) male networks. Their membership in these networks was part of the recruitment procedure for their candidacy for these high positions. Being part of a network was not sufficient, however. Each was asked to become a member of the executive board for specific reasons, one of which was gender. As one of the women said: "They were looking for a woman because there were no women on the board at that time, and they wanted more young board members." In other words, their recruitment was part of an effort by the respective boards to change the gender ratio. The women pointed out that an allmale board in a sport in which many women participate is no longer seen as legitimate. This is true only of all male boards, however, and not of boards with one woman member. An incumbent woman board member described what had happened before the recruitment procedure got under way for a new board member. She was consulted by other board members to see if she felt uncomfortable being the only woman board member and if she thought another woman should be added. She had said:

If you think I need another woman, you are wrong. I am fine. It is better to find the right person than [to select] a woman. I prefer someone who fits in the team; it does not matter if it is a man or a women.

Thus she was complicit with the same values and standards of the other (male) members. Such attitudes have ramifications for the subsequent entry of women to sport governance.

Although board membership of national sport associations is generally viewed as a prestigious task in the Netherlands (Anthonissen, 2006; Knoppers \& Anthonissen, 2001), these women were initially reluctant to consider the invitation to become a board member. One said: "I thought, 'Why do they ask me when they have only old guys on the board?" Another woman explained: "I actually accepted this job against my will, and I refused several times, because I didn't think much of the actual members of the executive board." In addition, some of these women did not want to join the board because of their perceptions of the role that they were expected to play on the board and because they knew they could be held responsible for unpopular board decisions. One of them explained:

They decided to reduce the number of board members from 7 to 5 . I was very busy when they asked me because I had a little girl, my mother was very ill, and I ran the household. I thought "If the situation is that I will be the only woman among four full-time working men, of whom there is always one or two missing, then I'll always be the scapegoat if anything goes wrong." So I said, "I do not want to be a member of the board if there are only five board members."

The women who were interviewed were very aware that, although they were supposed to be like "one of the men" with respect to their work experiences, their sport histories, and the structure of their domestic lives, they were not supposed to act like men in every sense once they were members of the board. These results do not necessarily mean that these women were not ambitious, but that they would only accept a board position under specific conditions. They thought that they had to be circumspect about expressing their personal ambitions and that they had to show that they had a passion for the job itself. One woman explained how ambitious behavior could be judged in a gendered way. She said:

You should never show that you are more qualified than the others because they will cut you down to size. 
You must show your commitment and enthusiasm instead. When women are too ambitious, it becomes hard for them to realize things; if they show they are modest, things happen. My experience shows you can come far, if you do it that way. It is clear that there are different expectations for the way men and women behave. Look at career patterns of men and women; a man is not worth anything if he shows no ambition, but about an ambitious woman, they say: "Here we have another bitch."

The results provided evidence that these women were aware that they could influence their chances and that these chances were gender-loaded. One woman applied for positions for which she knew few women would apply. She explained that the chances of (qualified) women to be chosen for such positions were great because these women are in demand and are seen as exceptions. She described how she realized her ambition to reach a higher position:

I know the dynamics; they are similar everywhere. I took all the steps that needed to be taken [to become a board member] but without further ambitions. Anything I undertake, I want to do well. Because I do it well, I am often asked to do other things. I think that is the way it works for women.

\section{Selection criteria}

The women believed that they were chosen as candidates (perceived fit) because they were women, had the necessary experience in sport, and/or occupied a high level paid position outside of sport. Most had advanced through various levels of board membership from local to provincial and national. As one of them said: "They knew me, because I had been a member of various committees, and they had read my name in the minutes. Of course they thought, 'This lady has a big mouth, but who the hell is she?" Those who became board members in the last few years did not have to take all the steps from a lower to a higher-level position to reach their actual position, as did their predecessors. All of them, however, had a paid professional position outside of sport and/or a master's degree. One woman said: “They were looking for a lawyer, because they needed help with contracts for sponsors." Women with similar backgrounds knew that they were in demand and could become members of executive boards in sport and non-sport associations because they had worked in financial sectors, had experience in governance, and/or had been in politics.

Another criterion that played a role in the selection of these women for positions on boards of national sport associations was the structure of their domestic lives. The interviewed women realized that male board members expected the female candidates to be available when they themselves were. One of the women said that her wish to have children was one of the issues that was discussed in her candidacy conversation. The candidacy committee made it clear that "they thought it would be very difficult [for a mother] to combine caring for young children with a board membership." Obviously, the degree of perceived fit was layered and complex, although it was presented as gender-neutral.

Although the women believed that they had to fit criteria made for and by male candidates, they had to meet other criteria as well. A woman explained:

They told me they wanted a woman on the board who was married, who had children, who had her master's degree, who had experience in the labor market, but was still a 'normal' woman and not a radical feminist or a battle-axe. .... also someone who does not get sidetracked by details. Maybe they thought I met these requirements. I never was a very dominant person, but I said what had to be said, or what I thought had to be said. Perhaps, there were not many individuals who did that in those days.

The foregoing quotation illustrates another dynamic of selection criteria. The women who were interviewed believed that they had to show that they were not outspoken and that they did not fit 'negative' images some men might have of women. A woman described her selection: "There were not many women in boards at all, and especially none who could say difficult things in a polite way. Perhaps that is why they wanted me."

\section{Domestic life}

These women were well aware of ways in which their domestic life could interfere with their work on the board and vice versa. Most of the women did not have children; those who did have them had waited until the children were older before they accepted a membership on a board. Most were also complicit with dominant patterns of domestic arrangements and agreed that women who have young children are not ideal candidates for board positions. They reasoned that the usual board membership of 4 to 8 years is difficult for mothers to combine with having a baby or caring for young children although they said little about fathers in similar situations.

These women had time to work as a board member because their male partner was willing to take over some of their domestic obligations. Each of the interviewed women consulted with her partner before she accepted board membership. None of them would have accepted a nomination if her partner had not agreed. A woman explained that her husband encouraged her to become a candidate because 
she was critical of the work of the existing board; board membership would give her the opportunity to prove that things can be done better. These women concluded that, in this sense, they had an exceptional partner. As one woman explained:

My husband settled it. He said, "You are made for that job, do not worry, it will turn out all right." Nevertheless, it was hard for him sometimes, because he had a time consuming job. There are not many men who like their wives to get into something like this.

Male board members probably require partner support for successful sport governance as well, but, as the quotation illustrates, male partners who are willing to give this kind of support may be more the exception than the rule. Wives may be expected to increase their domestic responsibilities when their husbands become board members. One interviewed woman expressed a different view, however. She attributed the responsibility for balancing the time demands of board membership to women themselves. She said:

I am not going to cook when I have a meeting and I am not at home for dinner. He is not handicapped! He can do it! Moreover, it does not matter if you have children; even then your husband can cook, find the children's sport clothes, et cetera. I never understood that. They are also his children.

Although this woman expressed another perspective, all of the women thought child rearing to be more a woman's than a man's responsibility. In this way, they were complicit with dominant ideas about men's and women's tasks and responsibilities and the separation between public and private lives. They were, therefore, a perceived fit only if their domestic responsibilities did not interfere with membership tasks.

\section{Taking the decision}

The initial resistance of the women to join the board was often dissolved by passion for their sport, by the perceived opportunities to actualize their visions about sport, and by the perception they were wanted as board members. "I thought 'If I say no, I may never get another chance,' and I had so many plans and ideas, so I thought 'I just have to do it." A woman described how her chair went to bat for her: "The chair of the board asked me to become a member. He had influence in the local clubs and thought he could get the other regions to vote for me. I never would have put myself up as a candidate." The perception they had of the situation influenced their strategy to become a member of the board. Often their love for a sport tipped the scale toward candidacy. As outsiders they negotiated board membership because they saw it as an opportunity do something for (women's) sport.

\section{Discussion}

Various factors enable a dominant group to control the access that a subordinate group has to positions of leadership (Witz, 1992). The results of the current study illustrate how incumbent male board members can keep control of the board by affirming and negating affirmative action policies and policing 'fit' during recruitment and selection processes. At the same time the results also illustrate how women may comply with these processes of recruitment and selection as they struggle to fit the demands made of board members. None questioned the criteria for selection. It is possible that those who did were not selected.

Strategies of the dominant group

\section{Toward affirmative action policy}

Although the IOC has mandated change in the gender composition of sport boards, the number of explicit measures taken to increase the number of women on the boards of Dutch national sport organizations has decreased in the past few years. The chairs involved in this study tended to comply with IOC recommendations to recruit more women to their boards to avoid having an all male board that was 'bad' for their image. They resisted the use of formal procedures and of affirmative action policies to create a gender balanced board however. Their main argument prioritized the 'quality' of the candidate who had to be found through the 'usual' procedures. Although they discussed the possible recruitment of women candidates, they also weakened that emphasis by arguing that 'quality' was gender-neutral. They asserted that women would be chosen when a man and woman candidate are equally qualified, but, at the same time, they argued that "abilities are never equal." Thus they resisted pressure from outside (IOC) to change the construction of the board by suggesting that their own procedures were gender-neutral and did not (implicitly) advantage men. With this strategy they were able to continue using their establishment, recruitment and selection methods, and in so doing, were able to reproduce themselves as dominant group. Even chairs of gender-balanced sports that were sensitive to the gender image of their board prioritized reducing gender skewness in theory only but not in practice. Once a board had one or two female members, the moral obligation seemed to be met, and relative little attention was paid to recruiting more women. 


\section{Toward recruitment and selection processes}

The women were selected in part because of their membership in predominantly male job or sport networks. Our results confirm other research that provides evidence that male networks are often an informal field where selection for high level and important board positions takes place. Rutherford (2001) found that limited access to men's networks is the greatest barrier for women in attaining management positions and that women managers are often unaware of these exclusionary practices. Sheridan and Milgate (2003) found that similar criteria were used to recruit men and women members for corporate boards, but that high visibility played a greater role in the selection of women than of men. In addition, although these recruitment criteria were presented as gender-neutral, men dominated these high powered jobs and continued to be selected for them. In other words, the criteria for membership of boards of directors tend to be related to a segment of the labor market where women are also under-represented and where 'old boys' networks play an important role. Yet the limited numbers of women who are part of male networks tend to become candidates for board membership only when they fit the right profile. The women in the current study were recruited because they were well educated, had high level jobs, had no young children, were flexible in their time schedule, and behaved 'properly.' They were not openly feminist, and they had experience with, knowledge about, and, commitment to their sport. In this manner, homologous reproduction can occur even when members of a subordinate group are involved.

The findings also echo the results of a study by Hovden (2000) of the gendering of selection processes for positions of leadership in Norwegian sport organizations. She found that leaders of the boards of sport organizations were expected to be result oriented, cooperative, courageous, determined, impartial, and loyal. They also had to have a good reputation, extensive social, business, and political networks, and various organizational experiences. Hovden characterized this as a 'male heavyweight' profile. Reproduction of the existing values in a board was guaranteed because only women who were perceived to 'fit' became members of male networks and were candidates for positions of leadership. Similarly, Power and Butterfield (2003) found that the greater the identification of women managers with characteristics associated with senior male managers, the better their chances of realizing their ambitions. Those who preferred alternative ways of managing were less likely to aspire to senior manager. In other words, only those who were seen as 'fitting' continued the climb up the organizational and occupational ladder. Thus, processes of identification with stereotypes associated with men and a distancing from those associated with women tend to shape the dynamics of selection processes and may explain the limited number of women available for positions of leadership such as board membership. Yet the 'fit' is never totally congruent because the visibility of a woman as member of a subordinate group marks her as different. Women board members in the current study could not completely identify with their male colleagues because they had to negotiate the stereotypical images held by these male chairs about women, child rearing, feminism, education, job experience, and the nature of board work.

Strategies of the subordinate group

\section{Toward recruitment and selection processes}

Women board members knew that they were chosen for a board membership because they were assumed to fit the profile of a suitable female candidate. In general, these women tended not to question, but to accept and adapt to, the criteria for candidacy. This is contrary to findings in other contexts. Sheridan and Milgate (2003), for example, found that women members of boards of directors of publicly listed companies in Australia were more concerned than men were about the lack of diversity in a governing board. Similarly, Acosta and Carpenter (2005) found that women athletic directors in U.S. colleges and universities expressed greater concern about the skewed gender ratio than did their male counterparts. In contrast, the women involved in the current study tended to be complicit with the recruitment and selection strategies used by the incumbent board members. They agreed that the 'fit' of a new candidate is more important than 'gender.' Mattis (in: Burke \& Mattis, 2000), who studied the behavior of women directors in organizations, called the complicity of women with dominant managerial behavior "a conspiracy of silence" (p.199). This complicity ensures homologous reproduction and perhaps explains why Wacjman (1998), in her study of senior managers, found few gender differences in managerial styles. This complicity, however, tended to help the women involved in the current study to gain a board membership and to convince them that these criteria were gender-neutral and resulted in equal opportunities for women and men to become board members. This complicity may also reflect the attitudes of the sectors in which they work. Fifty-nine percent of the employers (men and women) who work in Dutch (non-sport) organizations think that too much attention is paid to the position of women in organizations and that gender no longer plays a role in employment (Van der Lippe, 2004). This contradicts the fact that the percentage of women board members of these Dutch organizations is only $25 \%$ and at the corporate level it is 6.4\% (CDWI, 2004; Merens et al., 2004).

Besides possessing skills and qualities that ensure 'fit,' the women participating in the current study also had to 
have a domestic life that paralleled that of incumbent board members. Domestic responsibilities played an important role in determining 'fit.' Although the combination of board membership and domestic responsibilities is rarely seen as an issue for many men, these women had to develop a strategy to combine both responsibilities so that they could be 'free' (like their male counterparts) of responsibilities at the required times. These women were able to do this because they had an exceptional partner who was prepared to take on these domestic responsibilities when his wife had board meetings and similar obligations. At the same time, being a board member and having small children were seen as incongruent. This again reflects the wider societal context where Dutch women tend to choose activities and work that fit with their domestic responsibilities whereas men often choose activities that fit with their job responsibilities (Cloïn \& Boelens, 2004). Thus a board membership may have added value for men and mean more work and juggling for women.

The results of the current study provided evidence about women's frequent reluctance to become board members and the ways in which gender may play an important role in this reluctance. Although explanations for women's lack of interest in board membership are often framed as reflecting their own preferences and choices, structural and cultural contexts obviously play a significant role and may keep many women out of high-level positions of leadership in sport. Rutherford (2001) argued that women are more likely to want and to attain positions of leadership in organizational cultures that emphasize and create equal opportunities than in organizational cultures where gender differences are denied. The women involved in the current study were also aware of the gendered dynamics of board membership at such a high level and how they had to negotiate stereotypes to be considered a good 'fit.' According to Witz (1992), the subordinate group uses strategies to be included in groups from which they were originally excluded. In contrast, our research does not reveal a subordinate group that is eager to be included. Although they do have the ambition to influence a specific sport, these women only want to be included in the board under their own conditions.

Our results support Witz's (1992) contention that a dominant group attempts to keep control of a profession or activity in often invisible ways that need no justification. None of the women or men who were interviewed questioned the procedures or the criteria used for selection. These definitions of 'fit' tend not to be grounded in a systematic determination of the skills a board needs and a structured procedure but may have been based on the ways these men themselves qualified for board membership. These processes of negotiating fit not only reproduce existing (homogenous) boards but also reproduce gendered ways of selecting board members. Women who were chosen for candidacy had to fit a certain (contradictory) profile. They were chosen because of their skills and because they are women. If they had not been women, they might not necessarily have been chosen.

The attitudes of the chairs suggest that the number of women involved in high levels of sport governance will not increase drastically in the near future. Once a board has one or two members it may assume it has solved the image problem and has met its moral obligation of ensuring women's representation on the board. This resistance to women's participation in sport governance may reflect meanings given to sport as a primary activity. Messner (1988) has argued that, after women became athletes in large numbers, the ideological domination of sport by men shifted from the level of participation to leadership. Keeping women out of governance by declaring them as 'fit' for such positions only when token women are needed, strengthens male domination in sport.

In part, this gender skewness in sport governance perpetuates a peculiar form of injustice because sport is bifurcated into men's and women's sport, and women should be involved in the governance of their own sport. The resistance to women's significant involvement in sport governance also limits the social capital that women can accrue. Hoye (2002) has argued that board membership in the nonprofit sector, such as sport, creates social capital for these members. Women's exclusion from these boards not only prevents them from impacting the governance of sport but also from accruing highly valued social capital. The complicity with and lack of criticism of recruitment and selection procedures by both women and men involved in our study are also cause for concern. Possibly the general voluntary nature of sport participation and its accompanying perception of equal opportunity (Knoppers, 2006; Knoppers \& Anthonissen, 2001) and the specific experiences these leaders had had in sport that confirmed these meanings, may have reinforced a perceived gender neutrality of procedures in sport and produced it as a dominant 'common sense' manner of thinking.

The results indicated that, although the necessary qualities required for board membership, such as a strong track record, expertise in management and governance, a great deal of social capital, and high visibility (Sheridan, 2001; Sheridan \& Milgate, 2003; Vinnicombe \& Singh, 2003), seem to be similar in profit and nonprofit organizations, the manner in which women, as members of a subordinate group, and men, as members of a dominant group, may negotiate women's fit and their crossing of boundaries also depends a great deal on ways in which gender is practiced in a specific setting (Martin, 2001). If the primary activity of an organization is part of the construction of a desirable masculinity, such as occurs in sport, the boundaries of entry to governance may be more strongly policed than when the primary activity is 
associated with preferred femininity (Messner, 1988). The data suggest that boards negotiate to find a 'normal' woman, that is, a woman who 'fits' and who differs in some ways from what is perceived to be a stereotypical or 'average' woman.

Further research is needed to explore how strategies of fit and of control vary with meanings given to the primary activity and to governance. In addition, the dynamics between dominant and subordinate groups discussed here may also vary by the type of social relation under study. Little is known about how the ethnic majority as dominant group and ethnic minority as subordinate group negotiate fitness for candidacy and selection to positions of power. Do the gendered bifurcation of and meanings given to sport more strongly influence negotiations and perceptions of fit based on gender than on ethnicity? Further research is also needed on women who were considered as candidates for board membership but were not appointed. They were not part of this study, while they could give further insight into dynamics of exclusion. Finally, further research is needed to explore women's and men's strategies once they do govern together. Board memberships are usually 4-8 years long, which means that these women might be able to change the existing culture from within. Consequently, constructions of fit/lack of fit for board membership and of marginalization may also change.

\section{Appendix}

\section{Interview topics}

1. The process of entering the board: why, how and when, with whom and under which circumstances, recruitment and selection processes.

2. Affirmative action policy: what is done, how is it done, resistance, arguments and meanings, attitudes towards affirmative action.

3. Gendered meanings: meanings given to changes in the gender ratio and to board membership.

4. Private circumstances: description and organization of family life, housing, role of the partner, care for others such as children and parents.

5. (Paid) labor: relationship between board membership and (paid) labor/activities, organization of (paid) labor, priorities.

\section{References}

Acker, J. (1990). Hierarchies, jobs, bodies: A theory of gendered organizations. Gender \& Society, 4, 139-158.

Acker, J. (1992). Gendering organizational theory. In A. J. Mills \& P. Tancred (Eds.), Gendering organizational analysis (pp. 248262). Newbury Park, CA: Sage.
Acosta, V., \& Carpenter, L. J. (2005). Women in intercollegiate sport: A longitudinal, national study-Twenty-seven year update, 19772004. Retrieved August 22, 2005, from http://webpages.charter. net/womeninsport/.

Anthonissen, A. (2006). "The path to success": Shifting discourses in a football club. In A. Knoppers \& A. Anthonissen (Eds.), Making sense of diversity in organizing sport (pp. 29-43). Oxford: Meyer $\&$ Meyer.

Burke, R., \& Mattis, M. (Eds.) (2000). Women on corporate boards of directors: International challenges and opportunities, Dordrecht, The Netherlands: Kluwer Academic Publishers.

CDWI (2004). Women board directors of the future. Retrieved on June 15, 2006, from http://www.globewomen.com/cwdi/Global200_ KeyFindings.htm.

Cloïn, M., \& Boelens, A. (2004). Onbetaalde arbeid en de combinatie van arbeid en zorg [Unpaid labor and the combination of paid labor and care]. In W. Portegijs, A. Boelens, L., \& Olsthoorn (Eds.), Emancipatiemonitor 2004 (pp. 179-208). Den Haag, The Netherlands: Sociaal en Cultureel Planbureau \& Centraal Bureau voor de Statistiek.

Collinson, D., \& Hearn, J. (1996). Breaking the silence: On men, masculinities, and management. In D. Collinson \& J. Hearn (Eds.), Men as managers, managers as men: Critical perspectives on men, masculinities, and management (pp. 1-24). London: Sage.

Daily, C., \& Dalton, D. (2003). Women in the boardroom: A business imperative. Journal of Business Strategy, 24, 8-9.

Gamson, J. (1997). Messages of exclusion: Gender, movements, and symbolic boundaries. Gender \& Society, 11, 178-199.

Hovden, J. (2000). "Heavyweight" men and younger women? The gendering of selection processes in Norwegian sport organizations. NORA, Nordic Journal of Women's Studies, 8(1), 17-32.

Hoye, R. (2002). Board performance of Australian voluntary sport organizations. Unpublished doctoral dissertation, School of Leisure Studies, Griffith University, Australia.

Inglis, S. (1997). Roles of the board in amateur sport organizations. Journal of Sport Management, 11, 160-176.

Itzin, C. (1995). The gender culture in organizations. In C. Itzin \& J. Newman (Eds.), Gender, culture and organizational change: Putting theory into practice (pp. 30-53). London: Routledge.

Kanter, R. M. (1977). Men and women of the corporation. New York: Basic Books.

Kikulis, L. (2000). Continuity and change in governance and decision making in national sport organizations: Institutional explanations. Journal of Sport Management, 14, 293-320.

Knoppers, A. (2006). The skill levels of men are quite diverse: Gender and coaching. In A. Knoppers \& A. Anthonissen (Eds.), Making sense of diversity in organizing sport (pp. 58-70). Oxford: Meyer $\&$ Meyer.

Knoppers, A., \& Anthonissen, A. (2001). Meanings given to performance in Dutch sport organizations: Gender and racial/ ethnic subtexts. Sociology of Sport Journal, 18, 303-317.

Knoppers, A., \& Anthonissen, A. (2005). Male athletic and managerial masculinities: Congruencies in discursive practices? Journal of Gender Studies, 14, 123-136.

Martin, P. Y. (2001). 'Mobilizing masculinities': Women's experiences of men at work. Organization, 8, 587-618.

Martin, P. Y. (2003). 'Said and done' versus 'saying and doing': Gendering practices, practicing gender at work. Gender \& Society, 17, 342-366.

Merens, A., Cuijpers, M., \& Boelens, A. (2004). Politieke en maatschappelijke besluitvorming [Political and societal decision making]. In W. Portegijs, A. Boelens, \& L. Olsthoorn (Eds.), Emancipatiemonitor 2004 (pp. 179-208). Den Haag, The Netherlands: Sociaal en Cultureel Planbureau \& Centraal Bureau voor de Statistiek.

Messner, M. (1988). Sport and male domination: The female athlete as contested ideological terrain. Sociology of Sport Journal, 5, 197211. 
Nuijten, S., Lucassen, J., \& Van Kalmthout, J. (2004). Verenigingsmonitor 2003, de stand van zaken in de sportvereniging [Sport club monitor 2003: The state of affairs]. Arnhem, The Netherlands: NOC*NSF.

Power, G., \& Butterfield, D. (2003). Gender, gender identity, and aspirations to top management. Women in Management Review, $18,88-96$.

Rutherford, S. (2001). Organizational cultures, women managers and exclusion. Women in Management Review, 16, 371-373.

Sarra, J. (2005). Class act: Considering race and gender in the corporate board room. St. John's Law Review, 79, 1121-1160.

Sheridan, A. (2001). A view from the top: Women on the boards of public companies. Corporate Governance, 1, 8-14.

Sheridan, A., \& Milgate, G. (2003). 'She says, he says': Women's and men's views of the composition of boards. Women in Management Review, 18,147-155.

Van der Lippe, T. (2004). Emancipatiegezindheid van werkgevers [Attitudes of employers towards emancipation]. In W. Portegijs, A. Boelens, \& L. Olsthoorn (Eds.), Emancipatie- monitor 2004 (pp. 226-250). Den Haag, The Netherlands: Sociaal en Cultureel Planbureau \& Centraal Bureau voor de Statistiek.

Verweel, P. (2006). Sense making in sport organizations. In A. Knoppers \& A. Anthonissen (Eds.), Making sense of diversity in organizing sport (pp. 18-28). Oxford: Meyer \& Meyer.

Vinnicombe, S., \& Singh, V. (2003). Locks and keys to the boardroom. Women in Management Review, 18, 325-333.

Wacjman, J. (1998). Managing like a man: Women and men in corporate management. University Park, PA: Polity.

West, A., Green, E., Brackenridge, E., \& Woodward, D. (2001). Leading the way: Women's experiences as sports coaches. Women in Management Review, 16, 85-92.

White, A., \& Henry, I. (2004). Women, leadership, and the Olympic movement. Retrieved November 14, 2004, from http://www.lboro. ac.uk/departments/sses/institutes/salp/IOC lboro report.pdf.

Witz, A. (1990). Patriarchy and professions: The gendered politics of occupational closure. Sociology, 24, 675-690.

Witz, A. (1992). Profession and patriarchy. London: Routledge. 